\section{Implicit but not explicit exposure to threat conditioned stimulus prevents spontaneous recovery of threat potentiated startle responses in humans}

\author{
Oyarzún $\mathrm{JP}^{1,2, *}$, Càmara $\mathrm{E}^{2}$, Kouider $\mathrm{S}^{5}$, Fuentemilla $\mathrm{L}^{1,2,4}$, de Diego-Balaguer $\mathrm{R}^{1-4}$
}

${ }^{1}$ Dept. of Cognition, Development and Educational Psychology, University of Barcelona, 08035

Barcelona, Spain

${ }^{2}$ Cognition and Brain Plasticity Group, IDIBELL, Bellvitge Biomedical Research Institute, L'Hospitalet de Llobregat, 08097 Barcelona, Spain

${ }^{3}$ ICREA, Catalan Institution for Research and Advanced Studies, 08010 Barcelona, Spain

$3{ }^{4}$ Institute of Neurosciences, University of Barcelona, 08035 Barcelona, Spain

$4 \quad{ }^{5}$ Brain and Consciousness Group, Département d'Études Cognitives, École Normale Supérieure, PSL

5 Research University, 75005 Paris, France

$6 *$ Current affiliation: Psychology Department, New York University, New York, New York, 10003, US.

7

8

9 Corresponding author

10 Javiera P Oyarzún

11 Department of Cognition, Development and Educational Psychology

12 University of Barcelona,

13 Feixa Llarga s/n, 08907, L'Hospitalet (Barcelona), Spain

14 Phone: +34 934034768

15 Fax: +34 934021363

16 Email: javi.oyarzunb@gmail.com
17

18

19

20

21

22

23

24

25

26

27

28

29

30

31 
49

\begin{abstract}
It has long been posited that threat learning operates and forms under an affective and a cognitive learning system that are supported by different brain circuits. A primary drawback in exposure-based therapies is the high rate of relapse when higher order inhibitory structures failed to inhibit the emotional responses driven by the defensive circuit. It has been shown that implicit exposure of fearful stimuli leads to a long-lasting reduction of avoidance behavior in patients with phobia through the facilitation of fear processing areas in the absence of subjective fear. Despite the potential benefits of this approach in the treatment of phobias and PTSD, implicit exposure to fearful stimuli is still under-investigated. Here, we used unconscious presentation of threat-conditioned stimuli in healthy humans, using a continuous flash suppression technique. We found that implicit exposure of a conditioned stimulus reduced, on the following day, defensive responses to the conditioned stimulus measured by threatpotentiated startle responses but not by the electrodermal activity. Our results suggest that implicit exposure using CFS might facilitate the modulation of the affective component of fearful memories, representing an important therapeutic target to further advance exposurebased psychotherapies.
\end{abstract}

Keywords: threat-potentiated startle responses, electrodermal activity, skin conductance response, fear conditioning, threat conditioning, extinction learning, implicit exposure.

\title{
INTRODUCTION
}

The ability to learn that previously threatening stimuli are no longer a threat is critical for mental health since the disruption of this process can lead to anxiety disorders like phobias and post-traumatic stress disorder, PTSD. A long-standing critical issue in the treatment of threatrelated memories is the high rate of relapse after initially successful therapy (Craske and Mystkowski, 2006).

It has been established that threat learning operates and forms supported by two distinct brain circuits (Hamm and Vaitl, 1996; LeDoux, 1993). The first is an affective learning system grounded in the defensive circuit based in the amygdala and operating implicitly (LeDoux, 1993). The second is a cognitive learning system, associated with the acquisition of the declarative knowledge of stimuli contingencies, expectancy of threat and conscious experience 
67 of fear that is sustained by hippocampal and prefrontal brain areas (Baeyens et al., 1995; Lang

68 et al., 2000; LeDoux and Brown, 2017; Purkis and Lipp, 2001).

69

70 Exposure-based therapy is the most used procedure to treat threat-related memories (Rothbaum 71 and Davis, 2003) and is founded on the principles of extinction learning (Craske, 1999; Milad 72 and Quirk, 2012) where the threat-predicting stimulus (i.e., conditioned stimulus, CS) is 73 repeatedly presented in the absence of the negative outcome (e.g., unconditioned stimulus, US).

74 Through this procedure, subjects learn an inhibitory memory that, relying on prefrontal structures (e.g., dorsolateral and ventromedial prefrontal cortex) (Phelps et al., 2004; Schiller et

76 al., 2013), suppresses the expression of the defensive responses initiated by amygdala-

77 subcortical structures (Pare and Duvarci, 2012; Sotres-Bayon et al., 2006). However, this 78 inhibitory function often fails, and defensive responses are spontaneously recovered with the 79 passage of time (Rescorla, 2004).

81 It has been suggested that since extinction learning leaves the affective memory fairly intact 82 (Baeyens et al., 1995; Myers and Davis, 2002), such implicit trace could later motivate fear 83 recovery, especially when the inhibitory structures (i.e., the prefrontal cortex) are impaired, as is 84 the case with anxiety-related patients (Konarski et al., 2007; Sotres-Bayon et al., 2006), or under 85 stressful situations (J and Nadel, 1985). Some studies have shown that procedures that avoid 86 prefrontal cortex (PFC) engagement to inhibit threat-related memories are highly effective in 87 preventing the recovery of defensive responses to threat conditioned or phobic stimuli (Koizumi 88 et al., 2016; Schiller et al., 2013; Siegel and Weinberger, 2009). Of particular interest are the 89 works of Siegel and Weinberg (Siegel and Warren, 2013a, 2013b) showing that very brief 90 repeated masked exposure to phobic stimuli led to long-lasting reduction in avoidance 91 behaviour in spider-phobics. In a recent fMRI study, the authors (Siegel et al., 2017) suggested 92 that the beneficial effects of masked exposure might have been mediated through a facilitation 93 of threat memory processing and the activation of regulation areas as participants do not 
94

95

96

97

98

experience subjective distress during exposure. To date, however, implicit exposure is still under-investigated, harboring important theoretical as well as clinical implications.

Here, we investigated the effects of implicit exposure on a fearful memory after $24 \mathrm{~h}$, using a continuous flash suppression technique (CFS). To model fear acquisition and exposure-based therapy, healthy participants were threat conditioned on day 1 to fearful faces. On day 2 stimuli were presented through a stereoscope, either invisibly (through CFS) for the implicit group or explicitly for the explicit group. On day 3 participants were normally presented to threat conditioned stimuli and recovery of defensive responses were tested by analyzing threatpotentiated startle responses, electrodermal activity, and online expectancy reports.

As it has been suggested by other authors ("Anxious: The Modern Mind in the Age of Anxiety by Joseph E LeDoux, book review," n.d.; Brewin, 2001; Siegel et al., 2017), we predict that by restraining cognitive-mediated fear processing, implicit exposure would promote threat memory processing at the implicit level and hinder the recovery of defensive responses.

\section{MATERIALS AND METHODS}

\section{Participants}

Implicit group. Fifty-nine (46 female, $M=22.95$ years, $S D=3.78$ ) healthy students with normal or corrected-to-normal vision were recruited for this group. On the first day, we excluded 16 participants that did not meet the threat acquisition criteria (see exclusion criteria for acquisition). From these, 23 more participants were excluded on the second day because they broke the suppression effect during implicit exposure (see exclusion criteria for image suppression). A final sample of 20 participants fulfilled the criteria for inclusion and followed the three consecutive-days experimental protocol of the implicit group.

Explicit group. Thirty-two healthy students with normal or corrected-to-normal vision were recruited for this group ( 25 female, $M=20.5$ years, $S D=2.39$ ). On day 1 , we excluded 13 
121 participants that were not threat conditioned and three that were non-responders (see exclusion

122 criteria for acquisition). One participant did not return for day 3 . A final sample of 15

123 participants fulfilled the criteria for inclusion and followed the three consecutive-days

124 experimental protocol of the explicit group.

125 The study was approved by the Institute of Biomedical Research of Bellvitge ethics committee 126 and all subjects from both groups signed an informed consent before their participation.

\section{Psychological Inventories}

129 In order to control for psychological individual differences that could influence threat learning,

130 all participants completed the Spanish version of the Spielberger State-Trait (STAI-T), the

131 State-State (STAI-S) Anxiety Inventory (Spielberger, 1983) and the Spanish version of the 25-

132 item English Resilience Scale (Wagnild and Young, 1993) containing the 'Acceptance of Self

133 and Life' (ASL) and "Personal Competence" (PC) subscales.

135 Stimuli

136 Visual Stimuli. We employed Ekman's fearful faces (Ekman, 1976) as the conditioning stimuli

137 (CS) as they can be processed in the absence of awareness through a rapid subcortical amygdala route (McFadyen et al., 2017). Faces were presented for 5 seconds with inter-trial intervals (ITI) of 10-12 seconds (after electrodermal activity was stabilized). Stimuli order presentation was randomized with the constraint that no more than 3 repetitions of the same stimuli occurred. Stimuli were displayed on a 22-inch computer monitor (resolution $=1,024 \times 768$ pixels; refresh rate $=60 \mathrm{~Hz}$ ) and were controlled using Psychophysics Toolbox software (Brainard, 1997; Pelli, 1997). Stimulus contrast was equally set for all participants, at a level that was clearly visible (CFS) (see CFS in experimental task below). 
147 Electrical Stimulation. We used a mild electric shock to the wrist as the unconditioned stimulus

148 (US) during threat conditioning on day 1. Shocks were delivered through an electrode attached

149 with a Velcro strap to participants' dominant inner wrist, with a maximum intensity of $15 \mathrm{~mA}$

150 and 50 ms duration and co-terminated with faces presentation (Oyarzún et al., 2012). A Grass

151 Medical Instruments stimulator (Grass S48 Square Pulse Stimulator) charged by a stabilized

152 current was used with a Photoelectric Stimulus Isolation Unit (Model PSIU6). At the beginning

153 of the session, participants regulated shock intensity to a level which they described as very

154 uncomfortable yet not painful.

155 Air-puffs. In order to measure threat-potentiated startle responses (see below), we mechanically provoked blink responses by delivering $40 \mathrm{~ms}$ air-puffs, through a hosepipe directed to the anterior part of the temporal region between the outer canthus of the eye and the anterior margin of the auditory meatus (Haerich, 1994; Hawk and Cook, 1997) of the dominant-hand side. Airpuffs were delivered $4.5 \mathrm{~s}$ after every face presentation onset (did not overlap with electrical stimulations) and during every other intertrial interval (ITI). In order to habituate subjects to airpuff stimulation, each day started with 10 startle probes (Sevenster et al., 2012a).

\section{Experimental Task}

\section{Day 1. Fear acquisition}

165 On day 1, participants were randomly presented with 3 fearful faces, 8 times each. Two of them 166 (CS1 and CS2) co-terminated with a mild electric shock to the wrist on $75 \%$ of the trials 167 (reinforcement was omitted in the 1st and 5th trial) and a third one was never followed by the aversive stimulus (neutral stimulus, NS). Face gender was counterbalanced and randomized across participants. To acquire asymptotic levels of learning, participants were instructed that two faces were going to be followed, most of the time, by an electric shock, while the third one was safe (Figure 1).

Exclusion criteria for acquisition. The first exclusion criterion aimed to ensure that participants and startle potentiation to both threat-conditioned stimuli compared to neutral, this is; the 
average of the final 4 trials, in the acquisition session, for both CSs was greater than for the NS stimulus in the EDA or SR index. In addition, we excluded non-responder participants who showed below $0.02 \mu \mathrm{S}$ peak to peak amplitude in the EDA index in more than $75 \%$ of unreinforced trials during acquisition (Raio et al., 2012).

\section{Day 2. Exposure session}

\section{Implicit exposure group}

Twenty-four hours after threat conditioning, using a stereoscope and the CFS technique (see CFS below) participants were unconsciously exposed with only two of the images presented on day 1: CS1 and NS, 16 times each in the absence of electric shocks. In order to control for participants' awareness of the face presentation, we asked for a subjective report using the keyboard arrows. After each trial, they were asked: 'Do you think you might have seen a face?' 'Yes' or 'No', and then 'Was it a male or a female?' Subjects then indicated 'male' or 'female' and how sure they were of their answer with 'sure' or 'not sure'.

Detection task. In order to dissuade participants to voluntary explore the non-dominant eye (by closing one eye) and thus break the CFS effect, we included a simple detection task on the dominant eye during Mondrian display (see CFS below). Three seconds after Mondrian onset, a central grey dot would randomly change to a different color for 1 second. At the end of the three awareness questions participants had to answer whether the dot had turned to green or not; although no feedback was received after each response participants were encouraged to be accurate in this task. Participants were pre-trained for this task in the training session (see training session below).

Exclusion criterion for image suppression. To ensure full image suppression we excluded participants that answered, in at least one trial: 'yes' to the first question ('Do you think you might have seen a face?') and were correct and confident (answered 'sure') in indicating the gender of the perceived face. Following this selection criteria, all the participants included in the 
201 final sample reported not seeing anything besides the Mondrian at all trials; this is, for every

202 trial the participants included in the sample answered ' $N o$ ' to the first question (except for one

203 subject that answered seeing something on one trial), they all guessed faces at chance in the

204 second question (main percentage of hits $46.71 \% ; \mathrm{SD}=7.5 ;[34.38 \%-58.06 \%]$ ) and responded

205 to be 'not sure' about the guess in the third question. Participants learned to answer these 3

206 awareness questions during the training session on day 2.

Continuous Flash Suppression (CFS). We employed the continuous flash suppression (CFS)

technique, a binocular rivalry-based method capable of reliably suppressing visual awareness despite stimulus presentation for long periods of time (Fang and He, 2005; Lin and He, 2009; Tsuchiya and Koch, 2005). Using a mirror stereoscope (Stereoaids, Australia) placed $45 \mathrm{~cm}$ from the screen, we presented a continuously flashing colorful pattern (Mondrian) (at $10 \mathrm{~Hz}$ ) to the dominant eye and low-contrast (albeit visible) faces to the other, non-dominant eye. Mondrians were created with Matlab (MathWorks, Natick, MA) and the Psychtoolbox (Brainard, 1997; Pelli, 1997) and were presented for 5.5 seconds, starting $500 \mathrm{~ms}$ before face onset. In this manner, target faces were rendered invisible to the participants and thus processed without awareness. To determine eye dominance we used a sighting dominance test (Porac and Coren, 1976) where we asked participants to hold, with extended arms, a plastic board and look through a central small aperture to a picture placed on the wall at a 2-meter distance. The investigator would then cover one participants' eye at a time and ask for a subjective report of the image. If the image was no longer seen when covering a certain eye then that eye was considered dominant.

Training session. After the eye dominance test and before starting the experiment on day 2 , participants had a training session for 5 minutes to calibrate the stereoscope, ensure image suppression and familiarize participants with the task and questions. First, a black and white image of a zebra was presented to one eye and the zebra outline was presented to the other. The subjects adjusted the mirrors of the stereoscope using two knobs so that each eye in isolation saw either the full zebra or the full zebra outline, and with two eyes the zebra was aligned 
229 within the zebra outline. Then, subjects in both groups initiated a training sequence using 6

230 presentations of random objects (instead of the faces) where they were familiarized with the 3

231 awareness questions and, in the case of the implicit group, with the detection task.

\section{Explicit exposure group.}

233 Participants followed the same procedure as the implicit group (same number, ITI, and length of

234 stimuli presented through the stereoscope). However, for this group, face-pictures were explicitly presented. Mondrians were presented (in the dominant eye) for only $500 \mathrm{~ms}$ before 236 face-picture presentation, so faces were fully visible to the participants, for the following 5 237 seconds (the same duration as in the implicit group), in the non-dominant eye. In the same way, 238 as with the implicit group, the same three questions regarding picture awareness followed each

239 image presentation. In order to encourage participants to pay attention to faces presentation, this 240 group did not perform the color detection task. All participants reported seeing the faces at all 241 trials; this is, they answered 'Yes' to the first question (except for one subject that reported not 242 seeing a face on one trial), presented $100 \%$ accuracy in gender detection and were always sure 243 about their response.

\section{Day 3}

246 Spontaneous recovery test. After 24 hours we tested for recovery of defensive responses to all 247 stimuli. Participants were presented with the three faces they saw on the first day, 6 times each 248 in the absence of the shock. To remove attentional orienting effects on the first trials, an extra 249 presentation of the neutral stimulus, which was not included in the analysis, was presented at the 250 beginning of this session.

252 Online threat expectancy ratings. During the spontaneous recovery test participants had to indicate whether they expected to receive, or not, an electric shock after seeing each face on the screen. One second after face presentation the question 'Are you expecting to receive a shock?' 
255 appeared on the screen for 3 seconds. Participants answered, using the arrows of the keyboard,

256 'Yes', 'No' or 'I don’t know'.

258 Measures

259 Threat-potentiated startle responses (SR)

260 Startle responses were analyzed after delivery of air-puffs. We performed a monocular 261 electromyography (EMG) on the orbicularis ocular muscle of the dominant eye. A $6 \mathrm{~mm}$ $262 \mathrm{Ag} / \mathrm{AgCl}$ electrode filled with a conductive gel was placed $1.5 \mathrm{~cm}$ below the lower eyelid in line 263 with the pupil at forward gaze, a second electrode was placed $2 \mathrm{~cm}$ lateral to the first one 264 (center-to-center), and a signal ground electrode was placed on the forehead $2 \mathrm{~cm}$ below the 265 hairline (Blumenthal et al., 2005).

266 EMG data analysis for SR. Raw EMG data were notched and band-pass filtered $(28-500 \mathrm{~Hz}$,

267 Butterworth, $4^{\text {th }}$ order), and afterward rectified (converting data points into absolute values) and 268 smoothed (low-pass filter $40 \mathrm{~Hz}$ ) (Blumenthal et al., 2005). Peak blink amplitude was 269 determined in a 30-150 ms interval following air-puff delivery. EMG values were standardized 270 using within-participant $Z$ scores for each day, and outliers $(Z>3)$ were replaced by a linear 271 trend at point (Sevenster et al., 2012a). For comparisons between exposure on day 2 and 272 spontaneous recovery test on day $3, \mathrm{Z}$ scores were calculated using both exposure and recovery 273 test data. For comparisons within stimuli (CS1, CS2 and NS) on day 3, Z scores were calculated 274 using only recovery test data.

\section{Electrodermal activity (EDA)}

277 Electrodermal activity and EMG was sampled at $1000 \mathrm{~Hz}$ and was recorded during the whole 278 session using Brain Amps amplifiers. EDA was assessed using two $\mathrm{Ag}-\mathrm{AgCl}$ electrodes 279 connected to a BrainVision amplifier. The electrodes were attached to the middle and index 280 fingers of the non-dominant hand.

281 EDA data analysis. EDA waveforms were low-pass filtered $(1 \mathrm{~Hz})$ and analyzed offline with 282 Matlab 7.7. F. Single-trial changes in EDA were determined by taking the base-to-peak 
283 difference for a $4.5 \mathrm{~s}$ window after stimulus onset and before air-puff (or electric shock)

284 delivery. The resulting amplitude of the skin conductance response (SCR) value was

285 standardized using within-participant $\mathrm{Z}$ scores for each day, and outliers $(\mathrm{Z}>3)$ were replaced

286 by a linear trend at point (Sevenster et al., 2012a). As for EMG analyses, comparisons between

exposure on day 2 and spontaneous recovery test on day 3 used $\mathrm{Z}$ scores calculated using both exposure and recovery test data. For comparisons within stimuli (CS1, CS2 and NS) on day 3, Z scores were calculated using only recovery test data.

\section{Online US-expectancy ratings (OER)}

Since explicit evaluation of contingencies could affect learning during fear acquisition and extinction learning during exposure, expectancy ratings were made only during day 3. After each image presentation, the question "Are you expecting to receive an electrical shock?" appeared on the top of the screen for 3.5 seconds to which participants answered "Yes" (scored 3), "No" (scored 1) or "I don't know" (scored 2) using the keyboard. Participants were encouraged to maintain their hands over the keyboard at all times and to restrict hand and head movement as much as possible.

\section{RESULTS}

\section{Acquisition}

Equivalent levels of threat acquisition for conditioned stimuli in both groups and in both measures.

Threat Potentiated Startle responses (SR). A two-way mixed analyses of variance (ANOVA) with group (implicit versus explicit) as a between-subject factor and stimuli (CS1 CS2 and NS) as a within-subject factor showed equivalent levels of SR for both groups in the last 4 trials (all $\mathrm{p}$ values $>.1$ for group and group $\mathrm{x}$ stimuli interaction) but a main effect of stimuli $\left(\mathrm{F}_{(2,66)}=\right.$ 
$\left.p<.001 ; d=.76, \mathrm{CS} 2-\mathrm{NS} t_{34}=3.75 ; p=.001 ; d=.63\right)$.

Electrodermal activity (EDA). EDA analyses showed similar results. Responses were equivalent between groups (all $\mathrm{p}$ values $>.1$ for group and group $\mathrm{x}$ stimulus interaction) but a main effect of stimuli was observed $\left(\mathrm{F}_{(2,66)}=26.61 ; \mathrm{p}<.001 ; \mathrm{q}^{2}=.44\right)$ (Figure 3A). A RM-ANOVA stimulus $\left(\mathrm{F}_{(2,68)}=28.48 ; p<.001 ; \nabla^{2}=.45\right)$ where CS1 and CS2 showed equivalent responses (paired t-test $\left.t_{34}=.29 ; p=.76 ; d=.05\right)$ but greater than the NS (CS1-NS $t_{34}=6,04 ; p<.001 ; d=$ $\left.1.02, \mathrm{CS} 2-\mathrm{NS} t_{34}=5.88 ; p<.001 ; d=.99\right)$.

\section{Exposure session}

\section{Gradual overall decrease of responses during exposure session with no differences} between groups nor between stimuli, in both measures.

We then analyzed the course of extinction learning during exposure using a two-way mixed ANOVA with group (implicit versus explicit) as an inter-subject factor and stimulus (CS1 and NS) and time (first trials 1-2 and last trials 15-16) as intra-subject factors.

Threat Potentiated Startle reflex $(S R)$. We found no differences in responses between groups nor differential responding between stimuli (all $p$ values $>.5$ for group, stimulus, and group $\mathrm{x}$ stimulus interaction). When looking at differences across time we found a decrease in responses from beginning to end of the session (main effect of time; $\mathrm{F}_{(1,33)}=55.57 ; p<.001 ; 0^{2}=.62$ ) that was equivalent between groups and stimuli (all $p$ values $>$.1) (Figure 2B). groups nor between stimuli (all $p$ values $>.1$ for group, stimulus, and group $\mathrm{x}$ stimulus 
337 session (main effect of time; $\mathrm{F}_{(1,33)}=57.50 ; p<.001 ; \mathrm{Q}^{2}=.63$ ) that was equivalent between

338 groups and stimuli (all $p$ values $>.1$ ).

\section{Spontaneous Recovery Test}

341 To test the recovery of defensive responses on day 3, we compared the last trial of the exposure 342 session with the first trial of the spontaneous recovery test for CS1 and NS (Oyarzún et al., 343 2012; Schiller et al., 2010, 2013; Soeter and Kindt, 2011; Warren et al., 2014) (Figure 4).

344 We first compared recovery of defensive responses between groups, for the startle responses 345 and for the electrodermal activity. And secondly, we compared the differential responses 346 between the EDA and the SR measures within each group.

CS1, in the implicit group, showed no recovery of responses from the end of exposure session to the beginning of the recovery test. Only CS1 in the implicit group showed lower responses in comparison with CS2.

Threat potentiated Startle Reflex (SR). A two-way mixed ANOVA with group (implicit versus explicit) as a between-subjects factor, and phase (exposure and recovery test) and stimulus (CS1 and NS) as within-subject factors, revealed no main effect of group $\left(\mathrm{F}_{(1,33)}=.30, p=.58 \text {; }\right]^{2}=$ $.00)$. A main effect of phase $\left(\mathrm{F}_{(1,33)}=38.92 ; p<.001 ; \nabla^{2}=.54\right)$ that was equivalent between groups (phase $\mathrm{x}$ group $\left.{ }_{(1,33)}=1.06 ; p=.31 ;\right]^{2}=.03$ ) indicated that SR responses increased at recovery in both groups. However, we found a significant stimuli x group interaction $\left(\mathrm{F}_{(1,33)}=\right.$ 357 10.0098, $\left.p<.005 ;]^{2}=.23\right)($ Figure 4A-B). We thus compared stimuli responses between groups. Unpaired t-test showed similar responses for the NS in both groups $\left(t_{(33)}=1.52 ; p=\right.$ $1.13 ; d=.49)$ but lower responses for the CS1 in the implicit than the explicit group $\left(\mathrm{t}_{(33)}=-\right.$ $2.19 ; p=.03 ; d=.74)$. Intra-group comparison of stimuli showed, in the implicit group, lower responses for the CS1 in comparison with the NS $\left(t_{(19)}=-2.97 ; p=.008 ; d=.66\right)$. In contrast, 
similar responses for NS and CS1 were found in the explicit group $\left(t_{(14)}=1.68 ; p=.11 ; d=\right.$

$363.43)$, indicating that implicit but not explicit exposure reduced SR responses to CS1.

364 We then compared CS1 responses with CS2 on day 3; another homologous stimulus that was 365 equally threat conditioned in the first session, but that was not exposed to participants on day 2

366 (Figure 2C). A two-way mixed ANOVA with group (implicit versus explicit) and stimulus 367 (CS1, CS2 and NS, standardized within day 3) as a between and within-subject factors respectively, revealed a significant group $\mathrm{x}$ stimulus interaction $\left.\left(\mathrm{F}_{(2,66)}=3.93 ; \mathrm{p}=.02 ;\right]^{2}=.11\right)$. Whereas in the explicit group all stimuli (i.e. CS1 NS CS2) showed comparable high responses (all $\mathrm{p}$ values $>.1$ ), differences across stimuli were found in the implicit group (implicit $\mathrm{F}_{(2,38)}=$ $3.44 ; \mathrm{p}=.04 ; \mathrm{T}^{2}=.15$, explicit $\left.\left.\mathrm{F}_{(2,28)}=1.37 ; \mathrm{p}=.26 ;\right]^{2}=.09\right)$, where only CS1 showed reduced response compared to the CS2 $\left(t_{(19)}=-2.09 ; p=.04, d=.46\right)$ and NS $\left(t_{(19)}=-2.77 ; p=.01, d=\right.$ $.62)$.

EDA remained equivalent in both groups, with an overall increased activity from exposure session to recovery test but greater recovery for CS1s that was comparable to CS2s responses. as an inter-subject factor, and phase (exposure and test) and stimuli (CS1 and NS) as within factors revealed a main effect of phase $\left.\left(\mathrm{F}_{(1,33)}=70.04 ; \mathrm{p}<.001 ;\right]^{2}=.69\right)$, stimuli $\left(\mathrm{F}_{(1,33)}=\right.$ 15.98; $\left.\mathrm{p}<.001 ; \mathrm{T}^{2}=.32\right)$ and phase $\mathrm{x}$ stimuli interaction $\left(\mathrm{F}_{(1,33)}=18.02 ; \mathrm{p}<.001 ; \nabla^{2}=.35\right)$, but no differences were found between groups (all $p$ values $>.1$ for group, group $\mathrm{x}$ stimulus and, group x stimulus x phase interaction) (Figure $4 \mathrm{C}-\mathrm{D}$ ). We thus combined groups and compared stimuli responses between phases. As expected, responses significantly increased from the end of the exposure session to the recovery test in both stimuli (paired t-test NS $t_{(34)}=-5.37 ; p<$ $.001 ; d=-0.90$, CS1 $\left.t_{(34)}=-7.10 ; p<.001, d=-1.2\right)$. And, although responses between stimuli 
the recovery test were greater for CS1 than for NS $\left(t_{(34)}=3.93 ; p<.001 ; d=0.66\right)$. Thus, showing that in both groups, CS1 and NS, incremented EDA responses from the end of day 2 to test, but with greater recovery for CS1.

We then explored whether such recovery in the CS1 was similar to the response of its conditioned homologous CS2 on day 3 (Figure 3C). A mixed ANOVA with group and stimuli (CS1, CS2 and NS) showed no differences across groups (all $p$ values $>.5$ for group and group $\mathrm{x}$ stimulus interaction) but a main effect of stimulus $\left(\mathrm{F}_{(2,66)}=15.21 ; p<.001 ;\right.$ T $\left.^{2}=.32\right)$ that was driven by equal responses for CS1 and CS2 on day 3 (paired t-test $t_{(34)}=.70, p=.48, d=.11$ ) but greater than NS (CS1-NS $t_{(34)}=5.48, p<.001, d=.92$, CS2-NS $t_{(34)}=5.15, p<.001, d=$ .87). Thus, in the EDA measure, regardless of type of exposure, conditioned stimuli CS1 showed equivalent increased recovery than CS2 on day 3.

Comparisons between measures within groups. The implicit group showed a downmodulation of CS1 in the recovery test in the SR but not in the EDA. In contrast, the explicit group showed greater responses for CS1 and CS2 than NS in both the EDA and SR.

In order to directly compare the differential responses in the EDA and the SR measures we tested whether the recovery of defensive responses was different between measures within each group. We performed RM-ANOVA with measure (SR and EDA), phase (exposure and test) and stimulus (CS1 NS) as within-subject factor, separately for each group. The implicit group showed a main effect of stimuli $\left(\mathrm{F}_{(1,19)}=44.83, \mathrm{p}<.001 ; \mathrm{Q}^{2}=.70\right)$, and interestingly a significant interaction of stimulus $\mathrm{x}$ measure $\left(\mathrm{F}_{(1,19)}=8.81, \mathrm{p}<.01 ; \mathrm{Q}^{2}=.31\right)$ and stimulus $\mathrm{x}$ measure $\mathrm{x}$ phase $\left(\mathrm{F}_{(1,19)}=6.32, \mathrm{p}=.02 ; \mathrm{q}^{2}=.25\right)($ Figure $4 \mathrm{~A}-\mathrm{C})$. Follow-up paired t-test showed greater CS1 responses from exposure to test in the EDA measure $\left(\mathrm{t}{ }_{(19)}=-4.15, \mathrm{p}<\right.$ $.005 ; \mathrm{d}=-.92)$ but not in the SR measure $\left(\mathrm{t}{ }_{(19)}=-1.87, \mathrm{p}=.07 ; \mathrm{d}=-.42\right)$. In contrast, the NS showed increment of responses in both measures $\left(\mathrm{EDA} \mathrm{t}{ }_{(19)}=-4.13, \mathrm{p}=.001 ; \mathrm{d}=-.92 ; \mathrm{SR} \mathrm{t}_{(19)}\right.$ 
$414=-4.2, \mathrm{p}<.001 ; \mathrm{d}=-.95)$. Thus, indicating that CS1 responses were divergently down-

415 modulated in the SR index but not in the EDA.

416 The explicit group showed a main effect of phase $\left.\left(\mathrm{F}_{(1,14)}=66.65, \mathrm{p}<.001 \text {; }\right]^{2}=.82\right)$, stimuli $(\mathrm{F}$

$\left.417(1,14)=10.72, \mathrm{p}=.006 ; \mathrm{T}^{2}=.43\right)$ and again significant interactions of: stimulus $\mathrm{x}$ phase $(\mathrm{F}(1,14)=$

$\left.4188.32, \mathrm{p}=.01 ; \mathrm{\theta}^{2}=.37\right)$, stimulus $\mathrm{x}$ measure $\left(\mathrm{F}_{(1,14)}=7.66, \mathrm{p}=.01 ; \mathrm{T}^{2}=.35\right)$ and stimulus $\mathrm{x}$

419 phase $\mathrm{x}$ measure $\left(\mathrm{F}_{(1,14)}=5.25, \mathrm{p}=.03 ; \mathrm{Q}^{2}=.27\right)$ (Figure $\left.4 \mathrm{~B}-\mathrm{D}\right)$. First, we looked for stimuli

420 responses increments from the exposure session to test. In this case, significant increments were

421 found in both measures for both stimuli [CS1 (EDA $t_{(19)}=-6.77, p<.001 ; d=-1.51$; SR $t_{(19)}=$

$422-4.01, p=.001 ; d=-.89$ ), and NS (EDA $t_{(14)}=-3.59, p=.003 ; d=-.92$, SR $t_{(19)}=-3.74, p=$

$423.002 ; d=-.96)$. We then looked for stimuli responses between phases. In the recovery phase, we

424 found that whereas CS1 and NS responses were equivalent in SR (paired-t-test $t_{(14)}=-1.34, p=$

$425.20, d=-.34$ ) responses in the EDA were greater for the CS1 (paired-t-test $t_{(14)}=4.25, p=.001$,

$426 d=1.09$ ). Thus showing that the explicit group increased responses for both stimuli in both

427 measures but in the EDA the recovery was greater for the CS1.

429 Online Threat Expectancy Ratings (OER) on day 3

430 Participants' explicit contingency learning was not modulated by either implicit or explicit

431 exposure.

432 We then explored on day 3 whether participants expected to be shocked after the presentation of

433 the faces (Figure 5). A two-way mixed ANOVA with group (implicit versus explicit) as

434 between-subject factor and stimuli (CS1, CS2 and NS) and time (mean of the first 2 trials versus

435 mean of the last 2 trials) as within-subject factor showed no differences between groups (all $\mathrm{p}$

436 values $>.1$ for group, group $\mathrm{x}$ stimuli and group $\mathrm{x}$ time interaction). Thus, these results

437 indicated that our experimental manipulation did not affect OER. However we found a main

438 effect of stimuli $\left(\mathrm{F}_{(2,66)}=50.34 ; p<.001, \nabla^{2}=.33\right)$, time $\left(\mathrm{F}_{(2,66)}=16.25 ; p<.001,0^{2}=.33\right)$ and

439 stimuli $\mathrm{x}$ time interaction $\left(\mathrm{F}_{(2,66)}=5.16 ; p<.005, \nabla^{2}=.13\right)$. We thus explored stimuli responses 
440 across time. We found that participants expectancy scored for CS1 and CS2 stimuli decreased

441 from beginning to the end during the recovery session (CS1 $t_{(34)}=3.39, p<.005 ; d=.57, \operatorname{CS} 2 t$

$442 \quad(34)=3.72, \mathrm{p}<.005 ; \mathrm{d}=.63)$. Interestingly and congruent with the threat generalization

443 responses to the NS in the first trials of the recovery test, NS also showed a decrease of

444 responses from beginning to the end of session (NS $t_{(34)}=2.71, p=01 ; d=.45$ ), as some

445 subjects reported not to be sure of expecting to be shocked when presented with the NS (scored

$446=2$ ) in the first trials. As expected, although shock expectancy was similar between CS1 and

447 CS2 at both the beginning and end of the session (all p values $>.5$ ), NS scores were

448 significantly lower at both the beginning (CS1-NS $t_{(34)}=8.90, p<.001 ; d=1.52$, CS2-NS $t_{(34)}$

$449=8.44, p<.001 ; d=1.42)$ and end of the session $\left(\mathrm{CS} 1-\mathrm{NS} t_{(34)}=5.60, p<.001 ; d=.94, \mathrm{CS} 2-\right.$

450 NS $t{ }_{(34)}=5.23, p<.001 ; d=.88$ ). Thus, participants maintained the cognitive threatful

451 representation for conditioned stimuli from the beginning to the end of the session.

PSYCHOLOGICAL INVENTORIES

\section{Equivalent scores between groups}

455 Since anxiety traits have been previously related to aspects of implicit emotional learning (Raio 456 et al. 2013) we checked whether our participants presented equivalent scores between groups in

457 the psychological inventories. No significant differences were found between groups in any of 458 the psychological inventories (see Table 1 for descriptive statistics); participants showed similar scores in the Spanish version of the STAI-state Inventory (unpaired t-test; $t_{(33)}=-.55, p=.58, d$

$460=.19)$, the STAI-trait inventory $\left(t_{(33)}=-1.55, p=.12, d=.52\right)$ and the Spanish version of the

461 25-item English Resilience with ASL and PC subscales (Group, $\left.\mathrm{F}_{(1,33)}=.69 ; p=.41 ;\right]^{2}=.02$,

462 group $\mathrm{x}$ scale interaction, $\left.\left.\mathrm{F}_{(1,33)}=1.00 ; p=.32 ;\right]^{2}=.03\right)$.

463 These results indicate that the differences observed for the implicit and explicit groups are

464 unlikely to be due to differences in anxiety and resilience traits between the groups. 


\section{DISCUSSION}

468

469 Two groups of participants underwent a partial reinforced threat-conditioning paradigm using

470 three fearful faces. Two of the faces co-terminated with a mild electric shock to the wrist on

$47175 \%$ of trials (conditioned stimuli; CS1 and CS2) while a third face served as the neutral

472 stimulus (NS).

473 On the second day, one group of participants underwent implicit while the other underwent 474 explicit exposure to one of the threat conditioned stimulus. For the implicit condition, CS1 and

475 NS were presented unconsciously using the continuous flash suppression (CFS) technique and 476 no shocks were administered, while CS2 was not presented. The explicit group followed the 477 same procedure except that pictures were explicitly presented (see Materials and Methods 478 section). On the following day, we tested spontaneous recovery, by presenting all participants 479 explicitly with the three faces in the absence of electric shocks (see design in Figure 1). We used a combination of measures to examine defensive responses: threat-potentiated startle reflex 481 (SR), electrodermal activity (EDA) and online expectancy ratings (OER).

482

483 We found that exposing participants implicitly with previously threat conditioned stimulus 484 reduced the recovery of defensive responses after $24 \mathrm{~h}$, measured by SR, but not by EDA or 485 OER.

486 Our results highlight the divergent expression between two physiological measures (EDA and 487 SR) where implicit exposure only modulated threat potentiated SR. Dissociation between both 488 measures has long been recognized and although there is still much debate about the nature of 489 each measure it has been suggested that they are differently modulated by different neural 490 systems during threat memory encoding, extinction, and retrieval (Sevenster et al., 2014; Soeter and Kindt, 2010). 
492 In our experiment on day 3, EDA followed a similar pattern of responses as those presented by

493 the OER, but only at the beginning of the test session; higher responses for CS1 and CS2 than

494 for NS that gradually decreased throughout the session. Such correspondence across both

495 measures fits well with the idea that EDA is sensitive to modulations of threat explicit

496 expectancies (Lovibond, 2003; Sevenster et al., 2014; Soeter and Kindt, 2010). However, the

497 fact that OER and EDA, increasingly dissociated as the session progressed; with a stronger drop

498 in EDA to all stimuli (Figure 3) but sustained high OER (Figure 5) suggest that EDA reflects

499 subjective feelings of fear and it might behave independently from contingency knowledge, as

500 reported in other studies (Raio et al., 2012). Indeed, previous studies suggest that EDA is driven

501 by amygdala activity (Koizumi et al., 2016; Schiller et al., 2013).

502 Critically, the fact that implicit exposure only modulated SR in the first trial during the recovery

503 test might suggest that SR is more sensible than EDA, to subtle modulations in the affective

504 system, potentially induced during implicit exposure of CS1. In fact, SR as an automatic reflex,

505 has been considered to be tightly regulated by the defensive circuit reflecting amygdala activity

506 for negative affective valence (Hamm and Vaitl, 1996; Lang et al., 1990), whereas EDA appears

507 be more sensible to cognitive modulations by the explicit expectations of upcoming relevant

508 events (Sevenster et al., 2012b, 2014). Critically, if this is the case, our results would suggest

509 that implicit exposure might separately modulate the implicit trace of fearful memories.

511 Of note, NS showed an increment of defensive responses in the recovery test in both groups and

512 for both measures (when comparing the last trial of the exposure session with the first trial of

513 the spontaneous recovery test session), suggesting a global threat generalization effect.

514 Generalization in the physiological responses was further supported by the results in the OER

515 where participants reported to be 'not sure' of being shocked with NS presentation in the first

516 trials on day 3. Generalization of defensive responses in this type of paradigm has been

517 reported previously by other studies (Kindt and Soeter, 2013; Oyarzún et al., 2012; Soeter and

518 Kindt, 2011). In the context of our current design, it is possible that threat generalization was 
519 transferred via shared element among all stimuli (Dunsmoor and Murphy, 2015); this is, air-

520 puffs which were always presented at the end of each picture (to induce the blinking response)

521 (see Materials and Methods section), and were frequently followed by the electric shock (75\%

522 of times for the CSs).

523

524 An important point to consider is the fact that no differential responses between conditioned and

525 neutral stimuli, nor between groups (implicit vs explicit) were observed throughout the course

526 of the exposure session. One possible explanation is that the use of the stereoscope during

527 exposure (and not during day 1 or 3 ) added new contextual cues that impaired the retrieval of

528 threatful associations and precluded discrimination among stimuli. The use of the stereoscope

529 only on day 2 was aimed to increase ecological validity of the exposure task, as the acquisition

530 of fear associations and re-exposure to fearful stimuli would be unlikely to occur throughout a

531 stereoscope in a real context.

532

533 Our results are consistent with and build on previous studies using a very brief exposure (VBE)

534 approach, in which pictures of spiders were presented very rapidly (i.e., $25 \mathrm{~ms}$ ) in phobic

535 patients, leading to long-lasting reduction of avoidance behavior (Siegel and Warren, 2013a,

536 2013b). In an attempt to look for the mechanism underlying this effect, the authors (Siegel et al.,

537 2017) scanned patients while exposed to either masked or clear visible phobic stimuli (in two separated groups). Counterintuitively, they showed that presentations of either masked or visible phobic stimuli activated or deactivated, respectively, brain regions that support emotional

540 regulation like ventromedial PFC. They posited that limited awareness during exposure and lack

541 of subjective fear as well as amygdala activity reduction might facilitate fear processing and

542 emotional regulation. In addition, in other studies, it has been shown that when the prefrontal

543 cortex is not engaged during extinction learning (due to a lesion or due to early development

544 stage) subjects do not present recovery of defensive responses and amygdala is more involved

545 during extinction, leading to a permanent extinction (Kim and Richardson, 2010; Koenigs et al.,

546 2008). These results, point out the possibility that implicit exposure in our experiment might 
547 have engaged similar mechanism that leads to attenuation of defensives responses, albeit only

548 detected by SR measure.

549 Although the neural mechanism underlying CFS suppression effects are still largely unknown, a

550 functional neuroimaging study using CFS and invisible presentations of fearful faces (Lapate et

551 al., 2016) showed that while awareness of cues promoted PFC-amygdala functional

552 connectivity, invisible presentation of faces did not engage such regulatory circuit. In the case of

553 our implicit exposure paradigm, it is possible that faces are repetitively processed by the

554 amygdala, via a fast subcortical pathway (Méndez-Bértolo et al., 2016) and by sensory areas

555 representing CS while unaware and thus in the absence of activation of the defensive circuit.

556 This, in turn, would promote emotional memory processing perhaps by the desensitization of

557 low-level threat related regions, as posited by Siegel et al. 2017 (Siegel et al., 2017). In fact, it

558 has been reported that ex-spider phobic patients that showed permanent extinction after 6

559 months presented low activity in ventro-visual regions that were hyperresponsive to spiders

560 before the therapy. Further, the authors revealed that reduced activity in a restricted portion of

561 the same visual cortical region (right lateralized lingual gyrus) immediately after therapy

562 predicted long-term permanence of extinction learning (Hauner et al., 2012). These results

563 suggest that tapping into sensorial and low-level defensive networks might change the

564 association between stimulus and defensive response, leading to permanent extinction without

565 the need of prefrontal inhibitory control. As our experiment cannot account for any neural

566 mechanism underlying CFS exposure further research is still imperative to examine such

567 argument.

568 An important disadvantage and methodological limitation from CFS technique is that image 569 suppression is often broken when presenting threatful images (Yang et al., 2007) which might

570 limit its use as a sole tool in clinical settings. In our experiment, to reduce subject attrition by 571 image suppression failure, we implemented a task where participants had to report the color of a 572 central dot within the Mondrian. However, the fact that participants needed to hold their answer 573 for a couple of seconds, might have comprised higher cognitive demand load during image 
574 presentation. Whether this could have affected our results is unknown and more research would

575 be needed to clear out this possibility. Despite implementation of this task, around half of our

576 participants needed to be ruled out in this study for having broken the suppression effect. The

577 fact that the selection criteria eliminated so many participants might constitute a potential

578 confound as selected participants might share psychological features that make them more likely

579 to show reduced defensive responses in the SR during spontaneous recovery. Although our

580 selected participants rated equivalent scores in all psychological inventories, these results urge

581 the need for further investigation and replications that could circumvent bias selection of

582 participants by improving suppression effect during CFS exposure.

583 Our results deviate from those of Golkar \& Ohman (2012) (Golkar and Öhman, 2012). In their

584 experiment, the authors extinguished two conditioned stimuli; one under masked and the other

under visible conditions. In contrast to our results, in their study the stimulus that was unconsciously extinguished presented more fear recovery than the one explicitly extinguished.

587 However, it might well be the case that the parallel engagement of explicit and implicit learning could jeopardize the latter, as both explicit and implicit systems share encoding resources (TurkBrowne et al., 2006, p.) and might interact in a competitive manner (Kim and Baxter, 2001). Indeed, it has been suggested that the strong cognitive component of exposure-based therapies may actually preclude extinction learning at the implicit level ("Anxious: The Modern Mind in the Age of Anxiety by Joseph E LeDoux, book review,” 2015).

593 We believe that implicit exposure using CFS might promote processing of fearful memories in 594 the subcortical threat related networks and facilitate emotional regulatory areas. The fact that 595 fearful stimuli are experienced in the absence emotional distress in patients might help to 596 change the threatful trace and improve the course of the therapy. Although our results provide 597 encouraging evidence supporting these ideas, our findings call out the need for further 598 investigation to circumvent methodological limitations, precise the mechanism involved, and 599 uncover the potential of CFS implicit exposure as a valuable complementary procedure to 600 further advance exposure-based psychotherapies. 


\section{Acknowledgements}

604 The authors would like to thank Bert Molenkamp and David Cucurell for their technical

assistance and Dieuwke Sevenster and Joaquín Morís for their advice on the experimental

critical equipment for this study and Ivonne Heideman for helping during data collection.

608

609

610

611

612

613

614

615

616

617

618

619

620

621

622

623

624

625

626

627

628

629

630

631

632

633

634

635

636

637

\section{Author Contributions}

J.O. conducted the experiments and analyzed the data, J.O., R.D.B and L.F. designed the experiments and wrote the paper, and J.O., E.C., and S.K. programmed the task.

\section{REFERENCES}

Baeyens, F., Eelen, P., Crombez, G., 1995. Pavlovian associations are forever: On classical conditioning and extinction. J. Psychophysiol. 9, 127-141.

Blumenthal, T.D., Cuthbert, B.N., Filion, D.L., Hackley, S., Lipp, O.V., Van Boxtel, A., 2005. Committee report: Guidelines for human startle eyeblink electromyographic studies. Psychophysiology 42, 1-15. https://doi.org/10.1111/j.1469-8986.2005.00271.x

Brainard, D.H., 1997. The Psychophysics Toolbox. Spat. Vis. 10, 433-436.

Brewin, C.R., 2001. A cognitive neuroscience account of posttraumatic stress disorder and its treatment. Behav. Res. Ther. 39, 373-393. https://doi.org/10.1016/S00057967(00)00087-5

Craske, M.G., 1999. Anxiety disorders: Psychological approaches to theory and treatment. Basic Books.

Craske, M.G., Mystkowski, J.L., 2006. Exposure Therapy and Extinction: Clinical Studies, in: Craske, M.G., Hermans, D., Vansteenwegen, D. (Eds.), Fear and Learning: From Basic Processes to Clinical Implications. American Psychological Association, Washington, DC, US, pp. 217-233. https://doi.org/10.1037/11474-011

Dunsmoor, J.E., Murphy, G.L., 2015. Categories, concepts, and conditioning: how humans generalize fear. Trends Cogn. Sci. 19, 73-77. https://doi.org/10.1016/j.tics.2014.12.003

Ekman, P., 1976. Pictures of facial affect. Consult. Psychol. Press.

Fang, F., He, S., 2005. Cortical responses to invisible objects in the human dorsal and ventral pathways. Nat. Neurosci. 8, 1380-1385. https://doi.org/10.1038/nn1537

Golkar, A., Öhman, A., 2012. Fear extinction in humans: Effects of acquisition-extinction delay and masked stimulus presentations. Biol. Psychol. 91, 292-301. https://doi.org/10.1016/j.biopsycho.2012.07.007

Haerich, P., 1994. Startle Reflex Modification: Effects of Attention Vary With Emotional Valence. Psychol. Sci. 5, 407-410. https://doi.org/10.1111/j.1467-9280.1994.tb00294.x 
638

639

640

641

642

643

644

645

646

647

648

649

650

651

652

653

654

655

656

657

658

659

660

661

662

663

664

665

666

667

668

669

670

671

672

673

674

675

676

677

678

679

680

681

682

683

684

685

686

687

688

689

690
Hamm, A.O., Vaitl, D., 1996. Affective learning: Awareness and aversion. Psychophysiology 33, 698-710. https://doi.org/10.1111/j.1469-8986.1996.tb02366.x

Hauner, K.K., Mineka, S., Voss, J.L., Paller, K.A., 2012. Exposure therapy triggers lasting reorganization of neural fear processing. Proc. Natl. Acad. Sci. 109, 9203-9208. https://doi.org/10.1073/pnas.1205242109

Hawk, L.W., Cook, E.W., 1997. Affective modulation of tactile startle. Psychophysiology 34, 23-31. https://doi.org/10.1111/j.1469-8986.1997.tb02412.x

J, W., Nadel, L., 1985. Stress-induced recovery of fears and phobias. Psychol. Rev. 92, 512531. https://doi.org/10.1037/0033-295X.92.4.512

Kim, J.H., Richardson, R., 2010. New Findings on Extinction of Conditioned Fear Early in Development: Theoretical and Clinical Implications. Biol. Psychiatry, Posttraumatic Stress Disorder: Translational Neuroscience Perspectives on Gene-Environment Interactions 67, 297-303. https://doi.org/10.1016/j.biopsych.2009.09.003

Kim, J.J., Baxter, M.G., 2001. Multiple brain-memory systems: the whole does not equal the sum of its parts. Trends Neurosci. 24, 324-330. https://doi.org/10.1016/S01662236(00)01818-X

Kindt, M., Soeter, M., 2013. Reconsolidation in a human fear conditioning study: A test of extinction as updating mechanism. Biol. Psychol., SI: Human Fear Conditioning 92, 43-50. https://doi.org/10.1016/j.biopsycho.2011.09.016

Koenigs, M., Huey, E.D., Raymont, V., Cheon, B., Solomon, J., Wassermann, E.M., Grafman, J., 2008. Focal brain damage protects against post-traumatic stress disorder in combat veterans. Nat. Neurosci. 11, 232-237. https://doi.org/10.1038/nn2032

Koizumi, A., Amano, K., Cortese, A., Shibata, K., Yoshida, W., Seymour, B., Kawato, M., Lau, H., 2016. Fear reduction without fear through reinforcement of neural activity that bypasses conscious exposure. Nat. Hum. Behav. 1, 0006. https://doi.org/10.1038/s41562-016-0006

Konarski, J.Z., Mcintyre, R.S., Soczynska, J.K., Kennedy, S.H., 2007. Neuroimaging Approaches in Mood Disorders: Technique and Clinical Implications. Ann. Clin. Psychiatry 19, 265-277. https://doi.org/10.3109/10401230701653435

Lang, P.J., Bradley, M.M., Cuthbert, B.N., 1990. Emotion, attention, and the startle reflex. Psychol. Rev. 97, 377-395.

Lang, P.J., Davis, M., Öhman, A., 2000. Fear and anxiety: animal models and human cognitive psychophysiology. J. Affect. Disord., Arousal in Anxiety 61, 137-159. https://doi.org/10.1016/S0165-0327(00)00343-8

Lapate, R.C., Rokers, B., Tromp, D.P.M., Orfali, N.S., Oler, J.A., Doran, S.T., Adluru, N., Alexander, A.L., Davidson, R.J., 2016. Awareness of Emotional Stimuli Determines the Behavioral Consequences of Amygdala Activation and Amygdala-Prefrontal Connectivity. Sci. Rep. 6. https://doi.org/10.1038/srep25826

LeDoux, J.E., 1993. Emotional memory systems in the brain. Behav. Brain Res. 58, 69-79. https://doi.org/10.1016/0166-4328(93)90091-4

LeDoux, J.E., 2015. Anxious: The Modern Mind in the Age of Anxiety by Joseph E LeDoux, book review. Oneworld Publications.

LeDoux, J.E., Brown, R., 2017. A higher-order theory of emotional consciousness. Proc. Natl. Acad. Sci. 114, E2016-E2025. https://doi.org/10.1073/pnas.1619316114

Lin, Z., He, S., 2009. Seeing the invisible: The scope and limits of unconscious processing in binocular rivalry. Prog. Neurobiol. 87, 195-211. https://doi.org/10.1016/j.pneurobio.2008.09.002

Lovibond, P.F., 2003. Causal beliefs and conditioned responses: Retrospective revaluation induced by experience and by instruction. J. Exp. Psychol. Learn. Mem. Cogn. 29, 97106. https://doi.org/10.1037/0278-7393.29.1.97

McFadyen, J., Mermillod, M., Mattingley, J.B., Halász, V., Garrido, M.I., 2017. A Rapid Subcortical Amygdala Route for Faces Irrespective of Spatial Frequency and Emotion. J. Neurosci. 37, 3864-3874. https://doi.org/10.1523/JNEUROSCI.3525-16.2017 
691

692

693

694

695

696

697

698

699

700

701

702

703

704

705

706

707

708

709

710

711

712

713

714

715

716

717

718

719

720

721

722

723

724

725

726

727

728

729

730

731

732

733

734

735

736

737

738

739

740

741

742

743

744

Méndez-Bértolo, C., Moratti, S., Toledano, R., Lopez-Sosa, F., Martínez-Alvarez, R., Mah, Y.H., Vuilleumier, P., Gil-Nagel, A., Strange, B.A., 2016. A fast pathway for fear in human amygdala. Nat. Neurosci. https://doi.org/10.1038/nn.4324

Milad, M.R., Quirk, G.J., 2012. Fear Extinction as a Model for Translational Neuroscience: Ten Years of Progress. Annu. Rev. Psychol. 63, 129-151. https://doi.org/10.1146/annurev.psych.121208.131631

Myers, K.M., Davis, M., 2002. Behavioral and Neural Analysis of Extinction. Neuron 36, 567584. https://doi.org/10.1016/S0896-6273(02)01064-4

Oyarzún, J.P., Lopez-Barroso, D., Fuentemilla, L., Cucurell, D., Pedraza, C., RodriguezFornells, A., Diego-Balaguer, R. de, 2012. Updating Fearful Memories with Extinction Training during Reconsolidation: A Human Study Using Auditory Aversive Stimuli. PLOS ONE 7, e38849. https://doi.org/10.1371/journal.pone.0038849

Pare, D., Duvarci, S., 2012. Amygdala microcircuits mediating fear expression and extinction. Curr. Opin. Neurobiol., Microcircuits 22, 717-723. https://doi.org/10.1016/j.conb.2012.02.014

Pelli, D.G., 1997. The VideoToolbox software for visual psychophysics: transforming numbers into movies. Spat. Vis. 10, 437-442.

Phelps, E.A., Delgado, M.R., Nearing, K.I., LeDoux, J.E., 2004. Extinction Learning in Humans: Role of the Amygdala and vmPFC. Neuron 43, 897-905. https://doi.org/10.1016/j.neuron.2004.08.042

Porac, C., Coren, S., 1976. The dominant eye. Psychol. Bull. 83, 880.

Purkis, H.M., Lipp, O.V., 2001. Does Affective Learning Exist in the Absence of Contingency Awareness? Learn. Motiv. 32, 84-99. https://doi.org/10.1006/lmot.2000.1066

Raio, C.M., Carmel, D., Carrasco, M., Phelps, E.A., 2012. Nonconscious fear is quickly acquired but swiftly forgotten. Curr. Biol. CB 22, R477-479. https://doi.org/10.1016/j.cub.2012.04.023

Rescorla, R.A., 2004. Spontaneous Recovery. Learn. Mem. 11, 501-509. https://doi.org/10.1101/lm.77504

Rothbaum, B.O., Davis, M., 2003. Applying Learning Principles to the Treatment of PostTrauma Reactions. Ann. N. Y. Acad. Sci. 1008, 112-121. https://doi.org/10.1196/annals.1301.012

Schiller, D., Kanen, J.W., LeDoux, J.E., Monfils, M.-H., Phelps, E.A., 2013. Extinction during reconsolidation of threat memory diminishes prefrontal cortex involvement. Proc. Natl. Acad. Sci. U. S. A. 110, 20040-20045. https://doi.org/10.1073/pnas.1320322110

Schiller, D., Monfils, M.-H., Raio, C.M., Johnson, D.C., LeDoux, J.E., Phelps, E.A., 2010. Preventing the return of fear in humans using reconsolidation update mechanisms. Nature 463, 49-53. https://doi.org/10.1038/nature08637

Sevenster, D., Beckers, T., Kindt, M., 2014. Fear conditioning of SCR but not the startle reflex requires conscious discrimination of threat and safety. Front. Behav. Neurosci. 8. https://doi.org/10.3389/fnbeh.2014.00032

Sevenster, D., Beckers, T., Kindt, M., 2012a. Retrieval per se is not sufficient to trigger reconsolidation of human fear memory. Neurobiol. Learn. Mem. 97, 338-345. https://doi.org/10.1016/j.nlm.2012.01.009

Sevenster, D., Beckers, T., Kindt, M., 2012b. Instructed extinction differentially affects the emotional and cognitive expression of associative fear memory. Psychophysiology 49, 1426-1435. https://doi.org/10.1111/j.1469-8986.2012.01450.x

Siegel, P., Warren, R., 2013a. The effect of very brief exposure on experienced fear after in vivo exposure. Cogn. Emot. 27, 1013-1022. https://doi.org/10.1080/02699931.2012.756803

Siegel, P., Warren, R., 2013b. Less is still more: maintenance of the very brief exposure effect 1 year later. Emot. Wash. DC 13, 338-344. https://doi.org/10.1037/a0030833

Siegel, P., Warren, R., Wang, Z., Yang, J., Cohen, D., Anderson, J.F., Murray, L., Peterson, B.S., 2017. Less is more: Neural activity during very brief and clearly visible exposure to phobic stimuli. Hum. Brain Mapp. 38, 2466-2481.

https://doi.org/10.1002/hbm.23533 
Siegel, P., Weinberger, J., 2009. Very brief exposure: The effects of unreportable stimuli on fearful behavior. Conscious. Cogn. 18, 939-951. https://doi.org/10.1016/j.concog.2009.08.001

Soeter, M., Kindt, M., 2011. Disrupting reconsolidation: Pharmacological and behavioral manipulations. Learn. Mem. 18, 357-366. https://doi.org/10.1101/lm.2148511

Soeter, M., Kindt, M., 2010. Dissociating response systems: erasing fear from memory. Neurobiol. Learn. Mem. 94, 30-41. https://doi.org/10.1016/j.nlm.2010.03.004

Sotres-Bayon, F., Cain, C.K., LeDoux, J.E., 2006. Brain Mechanisms of Fear Extinction: Historical Perspectives on the Contribution of Prefrontal Cortex. Biol. Psychiatry 60, 329-336. https://doi.org/10.1016/j.biopsych.2005.10.012

Spielberger, C.D., 1983. Manual for the State-Trait Anxiety Inventory STAI (Form Y) ("SelfEvaluation Questionnaire").

Tsuchiya, N., Koch, C., 2005. Continuous flash suppression reduces negative afterimages. Nat. Neurosci. 8, 1096-1101. https://doi.org/10.1038/nn1500

Turk-Browne, N.B., Yi, D.-J., Chun, M.M., 2006. Linking Implicit and Explicit Memory: Common Encoding Factors and Shared Representations. Neuron 49, 917-927. https://doi.org/10.1016/j.neuron.2006.01.030

Wagnild, G.M., Young, H.M., 1993. Development and psychometric evaluation of the Resilience Scale. J. Nurs. Meas. 1, 165-178.

Warren, V.T., Anderson, K.M., Kwon, C., Bosshardt, L., Jovanovic, T., Bradley, B., Norrholm, S.D., 2014. Human fear extinction and return of fear using reconsolidation update mechanisms: The contribution of on-line expectancy ratings. Neurobiol. Learn. Mem., Extinction 113, 165-173. https://doi.org/10.1016/j.nlm.2013.10.014

Yang, E., Zald, D.H., Blake, R., 2007. Fearful expressions gain preferential access to awareness during continuous flash suppression. Emotion 7, 882-886.

https://doi.org/10.1037/1528-3542.7.4.882

\section{LEGENDS}

Figure 1. Three-day experimental design: acquisition exposure and spontaneous

recovery test. Two faces were fear-conditioned on day 1 (CS1 and CS2) whereas a third face served as the neutral stimulus NS. CS1 and the NS were presented with no reinforcement on the second day using a continuous flash suppression (CFS) setting (with a stereoscope and colorful patches). These Mondrians were continuously flashing during picture presentation in the implicit group but were fixed and briefly presented in the explicit group. Acquisition on day 1 and Recovery Test on day 3 were conducted explicitly with faces at the center of the screen and without CFS setting. 
783 Figure 2. Threat potentiated startle responses trial by trial throughout the 3-day 784 experiment for both experimental groups. The top panel depicts implicit exposure 785 group. The lower panel depicts explicit exposure group. Mean standardized startle 786 responses were calculated using all trials within each session for each group. Plots represent the mean response of (A) CS1 CS2 and NS during acquisition on day 1 (B) CS1 and NS during exposure on day 2 (C) CS1 CS2 and NS during spontaneous recovery on day 3. EMG: electromyography. Error bars represent standard error of the mean (SEM).

Figure 3. Trial-by-trial electrodermal activity throughout the 3-day experiment for both experimental groups. The top panel depicts implicit exposure group. The lower panel depicts explicit exposure group. Mean standardized electrodermal activity was quantified using all trials within each session for each group. Plots represent the mean electrodermal activity of (A) CS1 CS2 and NS during acquisition on day 1 (B) CS1 and NS during exposure on day 2 (C) CS1 CS2 and NS during spontaneous recovery on day 3. EDA: electrodermal activity. Error bars represent standard error of the mean (SEM). exposure and spontaneous recovery sessions for each group in each measure. Plots represent the last trial of exposure on day 2 and the first trial of spontaneous recovery on day 3. (A) Mean of startle response for the implicit group. (B) Mean of startle response for the explicit group (C) Mean of electrodermal activity for the implicit group. (D) 
807 Mean of electrodermal activity for the explicit group. EMG: electromyography; EDA:

808 electrodermal activity, small*: $\mathrm{p}<.05$ comparison for each stimuli between phases,

809 big*: main effect of phase. Error bars represent standard error of the mean (SEM).

810

811 Figure 5. Online threat expectancy ratings during recovery test. During each picture

812 presentation, subjects indicated whether they either expected (pressed 3), did not expect

813 (pressed 1) or were not sure about (pressed 2) imminent shock occurrence. Error bars

814 represent standard error of the mean (SEM); (a.u) arbitrary unit.

815

816

817

818

819

820 FIGURES

$821 \quad$ Figure 1. 
bioRxiv preprint doi: https://doi.org/10.1101/304592; this version posted April 20, 2018. The copyright holder for this preprint (which was not certified by peer review) is the author/funder, who has granted bioRxiv a license to display the preprint in perpetuity. It is made available under aCC-BY-NC-ND 4.0 International license.

822

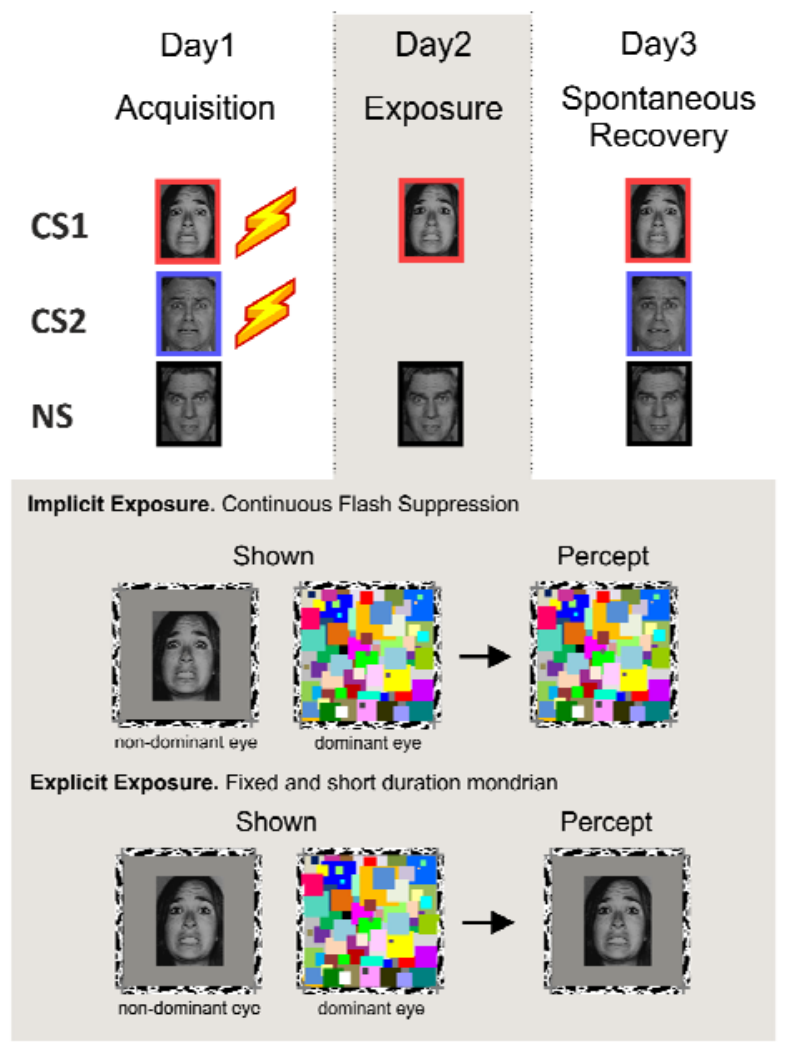

823

824

825

826

827

828

829

830 Figure 2. 

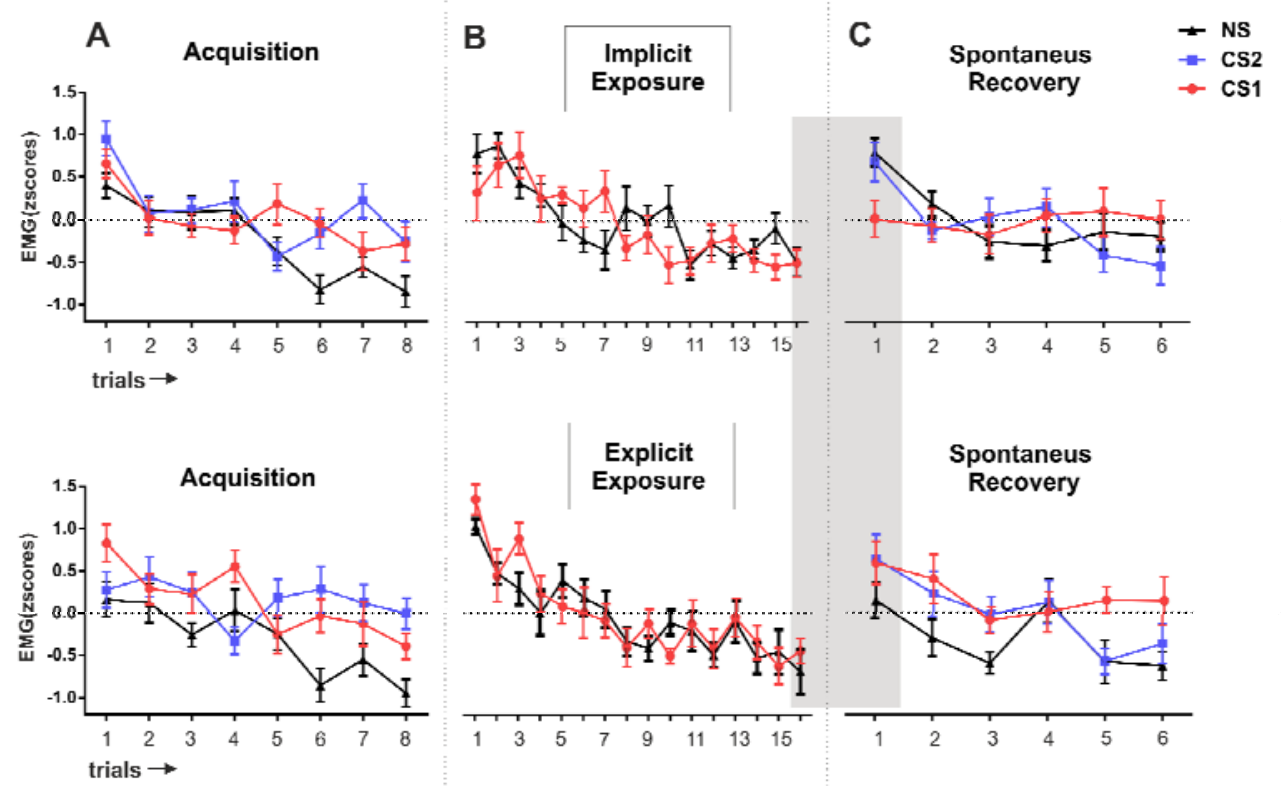

831

$832 \quad$ Figure 3.

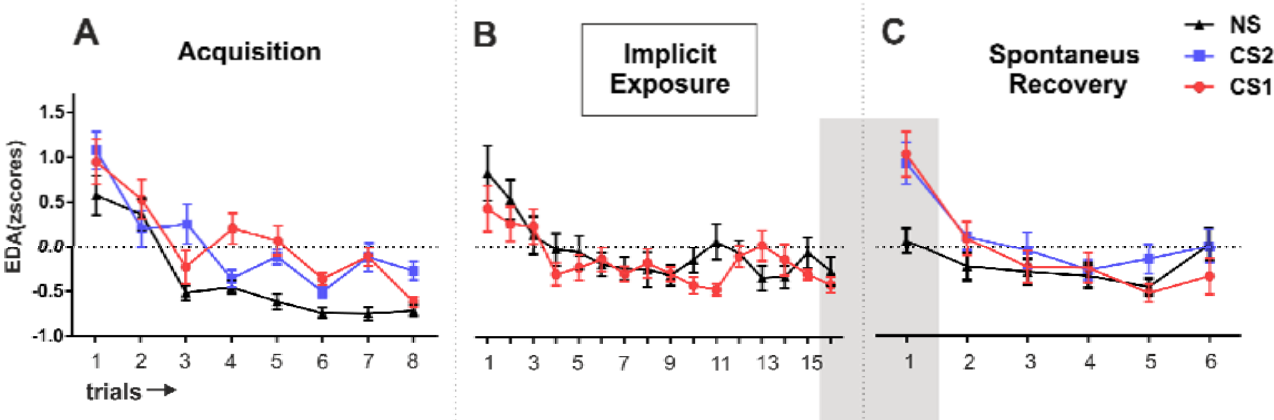

833
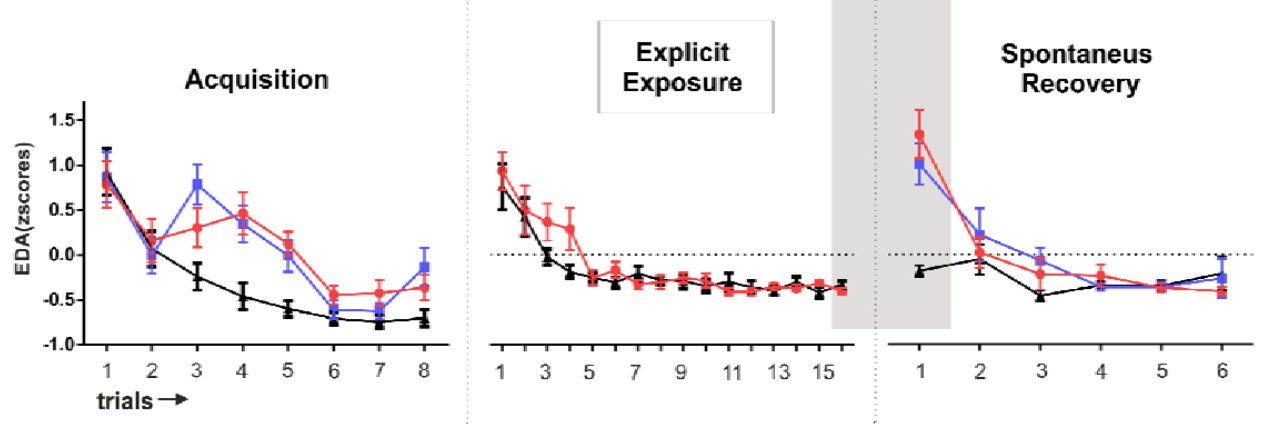

834

$835 \quad$ Figure 4. 
bioRxiv preprint doi: https://doi org/10.1101/304592; this version posted April 20, 2018. The copyright holder for this preprint (which was not certified by peer review) is the author/funder, who has granted bioRxiv a license to display the preprint in perpetuity. It is made available under aCC-BY-NC-ND 4.0 International license.

Spontaneus Recovery test

Implicit exposure group
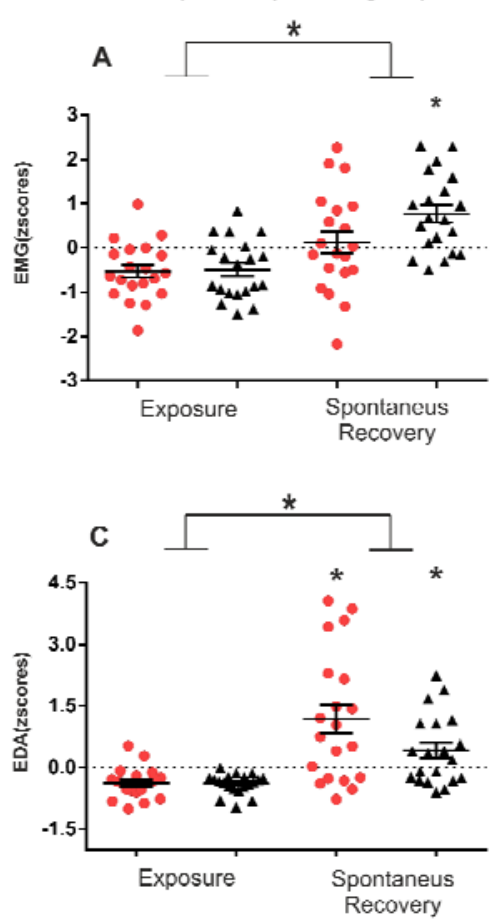

Explicit exposure group
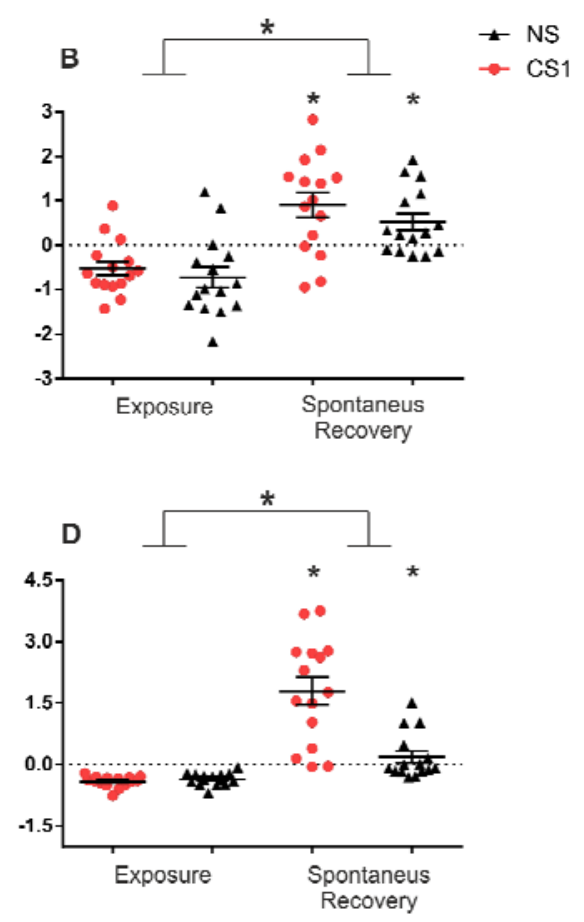

Figure 5.
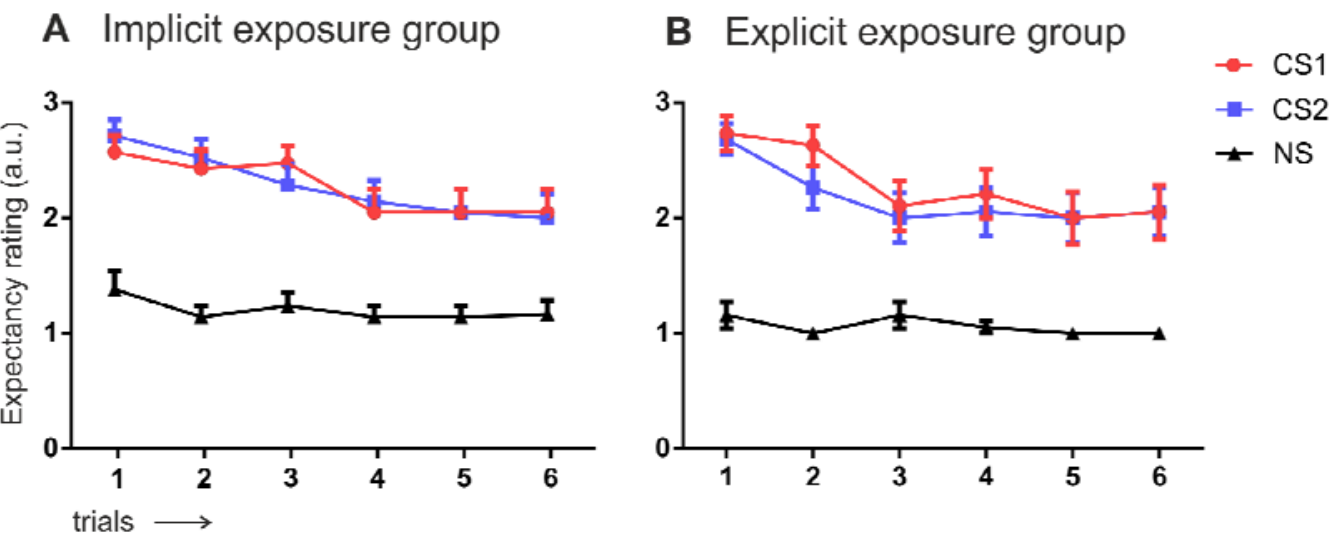
bioRxiv preprint doi: https://doi.org/10.1101/304592; this version posted April 20, 2018. The copyright holder for this preprint (which was not certified by peer review) is the author/funder, who has granted bioRxiv a license to display the preprint in perpetuity. It is made available under aCC-BY-NC-ND 4.0 International license.

\section{Table 1}

843 Descriptive statistics of inventory scores

\begin{tabular}{lcccc}
\hline & \multicolumn{2}{c}{ Implicit } & \multicolumn{2}{c}{ Explicit } \\
\hline Inventory & Mean & SD & Mean & SD \\
\hline STAI-state & 10.15 & 5.33 & 11.06 & 4.13 \\
STAI-trait & 9.7 & 7.6 & 13.0 & 3.4 \\
PC & 91.22 & 12.56 & 91.46 & 9.04 \\
ASL & 37.11 & 5.77 & 40.26 & 4.11
\end{tabular}

844

Note $:$ PC $=$ Personal Competence; ASL $=$ Acceptance of Self and Life

845

846

847

848 